\begin{tabular}{|c|c|c|c|c|}
\hline $\begin{array}{c}\text { Focus: Jurnal } \\
\text { Pekerjaan Sosial }\end{array}$ & ISSN: $2620-3367$ & Vol. 2 No: 2 & Hal: $208-218$ & Desember 2019 \\
\hline
\end{tabular}

\title{
PELAKSANAAN SUPPORT GROUP PADA ORANGTUA ANAK DENGAN CEREBRAL PALSY
}

\author{
Adina Riska Anindita \\ Program Studi Kesejahteraan Sosial FISIP Unpad \\ adina16001@mail.unpad.ac.id \\ Nurliana Cipta Apsari \\ Program Studi Kesejahteraan Sosial FISIP Unpad \\ nurliana.cipta.apsari@unpad.ac.id
}

\begin{abstract}
Abstrak
Keluarga, khususnya orangtua merupakan orang yang paling dekat dengan anak, sehingga orangtua memiliki peranan yang sangat penting di dalam kehidupan anak, terutama anak yang memiliki kondisi cerebral palsy. Namun, di sisi lain, orangtua yang memiliki anak dengan cerebral palsy memiliki peluang lebih besar untuk mengalami kondisi yang menyebabkan stres. Metode yang digunakan dalam jurnal ilmiah ini adalah dengan studi literatur. Agar dapat menjalankan peranannya sebagai orangtua bagi anaknya yang memiliki kondisi cerebral palsy, orangtua memerlukan dukungan sosial. Pekerja sosial dapat berperan dalam mengatasi hal ini yaitu dengan pemberian pelayanan kelompok melalui support group. Support group memiliki kekuatan penyembuhan karena orangtua yang memiliki anak dengan cerebral palsy akan mendapatkan dukungan yang sifatnya timbal balik.
\end{abstract}

Kata Kunci : Orangtua; Anak dengan Cerebral Palsy; Support Group.

\section{Abstrack}

Family, especially parents are the people closest to children, so parents have a very important role in the lives of children, especially children who have a condition of cerebral palsy. However, on the other hand, parents who have children with cerebral palsy have a greater chance of experiencing stressful conditions. The method used in this scientific journal is the study of literature. In order to be able to carry out its role as a parent for children who have cerebral palsy, parents need social support. Social workers can play a role in overcoming this, namely by providing group services through a support group. Support groups have therapeutic powers because parents who have children with cerebral palsy will get reciprocal support.

Keywords : Parents; Children with Cerebral Palsy; Support Group.

\section{Pendahuluan}

Anak yang memiliki kondisi disabilitas atau disebut dengan anak berkebutuhan khusus. Berdasarkan data dari BPS (Badan Pusat Statistik) pada tahun 2017, menyatakan bahwa jumlah anak berkebutuhan khusus $(\mathrm{ABK})$ di Indonesia mencapai angka 1,6 juta anak dengan beragam jenis gangguan.

Salah satu ragam jenis dari anak berkebutuhan khusus adalah anak dengan disabilitas fisik, khususnya cerebral palsy. Terdapat 17 juta orang dengan cerebral palsy tersebar di seluruh dunia (https://worldcpday.org/diakses pada Minggu 26 Mei 2019).Data Riset Kesehatan Dasar (Riskesdas) 


\begin{tabular}{|c|c|c|c|c|}
\hline $\begin{array}{c}\text { Focus: Jurnal } \\
\text { Pekerjaan Sosial }\end{array}$ & ISSN: $2620-3367$ & Vol. 2 No: 2 & Hal: $208-218$ & Desember 2019 \\
\hline
\end{tabular}

Kementrian Kesehatan RI pada tahun 2010 enunjukkan jumlah penyandang CP pada anak usia 24-

59 bulan adalah 0,09\% dari jumlah keseluruhan penduduk Indonesia dengan usia yang sama (Infodatin, 2014).

Cerebral palsy bukanlah sebuah penyakit yang mengancam jiwa, melainkan sebuah kondisi, kecuali anak yang terlahir dengan kasus yang sangat parah (Maimunah, 2013). Dikarenakan cerebral palsy ini adalah sebuah kondisi, maka kerusakan yang terjadi pada otak tidak bisa disembuhkan atau dengan kata lain bersifat permanen, namun perawatan dan terapi dapat membantu mengatur dampaknya pada tubuh. Cerebral palsy ini juga bukanlah sesuatu yang menular, karena cerebral palsy terjadi disebabkan adanya kerusakan pada perkembangan otak. Terdapat obat, terapi, dan teknologi yang dapat membatu anak dengan cerebral palsy bertahan hidup, seperti kursi roda, penyangga kaki, kawat gigi, dan lainnya. (Eliyanto \& Hendriani, 2013; Maimunah, 2013; Listiani \& Savira, 2015)

Anak dengan cerebral palsy akan mengalami gangguan motorik yang dikarenakan adanya kerusakan pada jaringan otak, khususnya pada pusat motorik atau jaringan penghubungnya. Kerusakan pada otak ini dapat terjadi pada masa kehamilan, persalinan atau selama proses pembentukan syaraf pusat. Anak dengan cerebral palsy juga bisa mengalami berbagai gangguan penyerta, yaitu gangguan kognitif dan gangguan fisik. (Eliyanto \& Hendriani, 2013).

Anak dengan cerebral palsy memiliki kondisi fisik yang berbeda dengan anak tanpa cerebral palsy. Kondisi fisik anak cerebral palsy akan berbeda tergantung pada tingkatan kondisinya, tetapi sebagian besar anak dengan cerebral palsy tidak mampu bergerak dan beraktivitas dengan bebas (Maimunah, 2013). Anak dengan cerebral palsy biasanya memiliki kesulitas dalam memegang objek, merangkak, dan berjalan. Selain itu, anak dengan cerebral palsy memiliki kelemahan dalam mengendalikan otot pada tenggorokkan, mulut, dan lidah yang menyebabkan anak dengan cerebral palsy tampak selalu berliur, kesulitas makan, dan menelan (Maimunah, 2013). Hal ini akan menyebabkan gangguan nutrisi berat pada anak dengan cerebral palsy (Bagnara, Bajraszewski, Carne, Fosang, Kennedy, Ong, Randall, Reddihough, \& Touzel, 2000 dalam Maimunah, 2013).

Pada anak cerebral palsy yang memiliki gangguan penyerta, anak tersebut tidak terlalu terganggu dengan kondisinya, karena ia tidak bisa membandingkan dirinya dengan orang lain. Namun pada anak dengan cerebral palsy murni atau tanpa gangguan penyerta, anak akan merasakan bahwa dirinya berbeda dengan orang lain. Anak tersebut bisa membandingkan dengan anak pada umumnya, karena anak cerebral palsy murni ini bisa berbicara,

mendengar, dan berpikir seperti anak-anak pada umumnya. Apabila tidak ditangani dengan tepat, maka kondisi psikologis anak dengan cerebral palsy ini akan terganggu. Di sini lah peran keluarga, khususnya orangtua sangat besar bagi anaknya, khususnya orangtua yang memiliki anak dengan kondisi cerebral palsy (Maimunah, 2013).

Menurut Lestari (2012), keluarga dapat dibagi menjadi dua jenis yaitu keluarga inti (nuclear family) dan keluarga batih (extended family). Keluarga inti adalah keluarga yang di dalamnya hanya terdapat tiga posisi sosial, yaitu suami-ayah, istri-ibu, dan anak (Lee, 1982, dalam Lestari, 2012). Sedangkan keluarga batih adalah anggota keluarga besar, seperti kakek, nenek, paman, atau bibi (Inayah, 2011). Anak dengan kondisi cerebral palsy bisa saja dirawat oleh orangtua (ayah dan ibu) dari keluarga inti, ataupun orang tua yang merawat yang berasal dari keluarga batih.Selanjutnya, menurut Allender (1998, dalam Vani, Raharjo, Hidayat, \& Humaedi, 2016), keluarga memiliki fungsi-fungsi yaitu fungsi pendidikan, sosialisasi, afeksi dan rekreasi, ekonomi, perlindungan dan pemeliharaan, dan status sosial. Oleh karena itu peran keluarga, khususnya orangtua (baik yang berasal dari keluarga inti ataupun keluarga batih) sangat berpengaruh besar dalam tumbuh kembang anak (Susilowati, 2007). Anak dengan cerebral palsy memiliki sebuah keunikan dan kebutuhan tersendiri, berbeda dengan anak lainnya, sehingga pola pengasuhan yang perlu dilakukan oleh orangtua kepada anak juga akan berbeda dengan anak tanpa kondisi dengan cerebral palsy (Eliyanto \& Hendriani, 2013). Dengan demikian, sangat penting bagi orangtua untuk mengetahui pengetahuan dan memiliki keterampilan yang tepat untuk mengasuh anak, khususnya anak dengan cerebral palsy. Sungguh tidak ada yang lebih terkena dampak dari adanya seorang anak berkebutuhan khusus daripada keluarganya sendiri (Fine \& Simpson, 2002; Turnbull \& Turnbull, 1997; Hardman, dkk, 2002, dalam Hidayati, 2011).

Selain harus menghadapi dinamika psikologis yang berasal dari lingkungan internal, orangtua juga akan mengalami berbagai dinamika psikologis yang berasal dari lingkungan eksternal, yaitu respon masyarakat. Tidak bisa dipungkiri, masyarakat terkadang bisa bereaksi kurang pantas terhadap anakanak yang memiliki kebutuhan khusus. Menurut Vani dkk (2016), anak dengan disabilitas tidak merasakan diterima secara penuh di lingkungan keluarga terutama orangtua. Orangtua menganggap anak dengan disabilitas merupakan "aib" bagi keluarga. Begitu juga dengan stigma negatif bahwa anak dengan disabilitas hanya dapat menunggu bantuan saja dan tidak bisa melakukan aktivitas sendiri. Reaksi orangtua 


\begin{tabular}{|c|c|c|c|c|}
\hline $\begin{array}{c}\text { Focus: Jurnal } \\
\text { Pekerjaan Sosial }\end{array}$ & ISSN: $2620-3367$ & Vol. 2 No: 2 & Hal: $208-218$ & Desember 2019 \\
\hline
\end{tabular}

mempunyai anak dengan disabilitas juga bermacammacam (Vani, Raharjo, Hidayat, \& Humaedi, 2016).

Selain orangtua harus bisa menghadapi berbagai dinamika yang berasal dari lingkungan internal dan eksternal, dan perlu memahami dan menerima kondisi anaknya. Orangtua juga diharapkan dapat bertindak sebagai terapis, apabila tidak bisa, setidaknya orangtua perlu menjadi manajer dari anak dengan cerebral palsy yang dapat menghubungan berbagai kebutuhan anak pada sumber terkait. Orangtua juga perlu menyediakan sumber daya untuk membantu perkembangan anak. Untuk menghadapi kondisi tersebut, orangtua dari anak dengan cerebral palsy memerlukan kebutuhankebutuhan tersendiri. Pada umumnya, orangtua yang memiliki anak dengan cerebral palsy membutuhkan beberapa hal yaitu terkait dana, informasi tentang cerebral palsy dan bagaimana penanganannya, dukungan secara emosional, dan bantuan-bantuan lainnya (Hidayati, 2011).

Mengingat banyak hal yang harus dihadapi dan dilakukan oleh orangtua yang memiliki anak dengan cerebral palsy, terkadang orangtua lupa untuk memperhatikan pula kondisi kesehatan dan kesejahteraan dirinya. Sehingga, tidak sering dijumpai bahwa orangtua yang memiliki anak disabilitas, khususnya anak dengan cerebral palsy lebih rentan terkena stress (Susilowati, 2007). Terlebih lagi, karena kondisi anak dengan cerebral palsy ini bersifat menetap atau tidak bisa disembuhkan, artinya orangtua perlu menghadapi kondisi seperti itu dari anaknya masih kecil hingga dewasa. Maka, perlu ada sebuah sistem dukungan yang dapat orangtua akses. Oleh karena itu, agar orangtua yang memiliki anak dengan cerebral palsy dapat lebih terpenuhi kebutuhan- kebutuhannya, maka diperlukan sebuah kelompok pendukung atau support group (Hidayati, 2011). Tujuannya adalah agar para orangtua yang memiliki anak dengan cerebral palsy memperoleh dukungan yang tepat sehingga kebutuhannya dapat terpenuhi. Dengan orangtua terpenuhi kebutuhannya, maka orangtua dapat melakukan perannya sebagai orangtua dengan baik. Sehingga, anaknya yang memiliki kondisi cerebral palsy dapat mengalami perkembangan yang baik. Dengan demikian, anak dengan cerebral palsy bukan saja mendapatkan pelayanan langsung dari terapis dan sekolah, juga mendapatkan pelayanan dari orangtua masing-masing, sehingga diharapkan akan memberikan pengaruh yang lebih baik dan optimal terhadap perkembangan anak dengan cerebral palsy.

\section{Pembahasan}

\section{Anak dengan Cerebral Palsy}

Undang-Undang No. 8 Tahun 2016, menjelaskan bahwa penyandang disabilitas adalah setiap orang yang mengalami keterbatasan fisik, intelektual, mental, dan/atau sensorik dalam jangka waktu lama yang dalam berinteraksi dengan lingkungan dapat mengalami hambatan dan kesulitan untuk berpartisipasi secara penuh dan efektif dengan warga negara lainnya berdasarkan kesamaan hal. Di dalam undang-undang ini juga dijelaskan mengenai ragam jenis disabilitas yaitu disabilitas fisik, disabilitas intelektual, disabilitas mental, dan disabilitas sensorik.

Berdasarkan data dari BPS (Badan Pusat Statistik) pada tahun 2017, menyatakan bahwa jumlah anak berkebutuhan khusus (ABK) di Indonesia mencapai angka 1,6 juta anak dengan beragam jenis gangguan. Salah satu ragam jenis anak berkebutuhan khusus adalah anak dengan cerebral palsy yang tergolong ke dalam disabilitas fisik. Terdapat 17 juta orang dengan cerebral palsy tersebar di seluruh dunia ${ }^{2}$.Data Riset Kesehatan Dasar (Riskesdas) Kementrian Kesehatan RI pada tahun 2010 menunjukkan jumlah penyandang CP pada anak usia 24-59 bulan adalah 0,09\% dari jumlah keseluruhan penduduk Indonesia dengan usia yang sama (Infodatin, 2014).

Cerebral palsy atau bisa disebut dengan $\mathrm{CP}$ bukanlah sebuah penyakit, melainkan sebuah kondisi yang cukup jarang ditemui. Cerebral palsy adalah hasil dari kerusakan otak atau kecacatan otak yang paling banyak terjadi ketika seseorang masih di dalam kandungan atau ketika dilahirkan, walaupun ada beberapa kasus yang mengalami CP bukan dari bawaan lahir. Penelitian terkini menunjukkan bahwa sebagian besar cerebral palsy dihasilkan dari perkembangan otak yang abnormal atau kerusakan otak pada saat melahirkan. Selain itu, kecelakaan, kekerasan, malpraktek, kelalaian, infeksi, dan cedera juga diketahui menjadi penyebab yang menyebabkan terjadinya cerebral palsy (https://www.cerebralpalsy.org, diakses pada 25 Mei 2019).

Menurut (Clark 1964, dalam Sriwidodo, 1985), cerebral palsy merupakan suatu keadaan kerusakan jaringan otak pada pusat motorik atau jaringan penghubungnya, yang terjadi pada masa prenatal, saat persalinan atau selama proses pembentukan syaraf pusat, ditandai dengan adanya 


\begin{tabular}{|c|c|c|c|c|}
\hline $\begin{array}{c}\text { Focus: Jurnal } \\
\text { Pekerjaan Sosial }\end{array}$ & ISSN: $2620-3367$ & Vol. 2 No: 2 & Hal: $208-218$ & Desember 2019 \\
\hline
\end{tabular}

paralisis, paresis, gangguan kordinasi atau kelainan-kelainan fungsi motorik.

Anak dengan kondisi cerebral palsy akan mengalami gangguan dalam pergerakannya. Cerebral palsy mempengaruhi otot dan kemampuan seseorang untuk mengontrolnya. Otot anak dengan cerebral palsy dapat berkontraksi secara berlebihan, atau sangat sedikit, atau semuanya di saat bersamaan. Anggota tubuh dapat menjadi kaku, membentuk posisi yang aneh. Kontraksi otot yang berfluktuasi dapat membuat anggota tubuh gemetar, goyang, dan bergelayut. Keseimbangan, postur, dan koordinasi tubuh juga dapat dipengaruhi oleh cerebral palsy. Kegiatan seperti berjalan, duduk, atau mengambil sebuah objek akan sulit dilakukan. Anak dengan cerebral palsy juga berpotensi untuk mengalami kedisabilitasan lainnya seperti gangguan intelektual, kejang, gangguan penglihatan dan pendengaran (https://www.cerebralpalsy.org, diakses pada 25 Mei 2019).

\section{Penyebab Kondisi Cerebral Palsy}

Cerebral palsy adalah hasil dari kerusakan otak atau kecacatan otak yang paling banyak terjadi ketika seseorang masih di dalam kandungan atau ketika dilahirkan, walaupun ada beberapa kasus yang mengalami CP bukan dari bawaan lahir. Penelitian terkini menunjukkan bahwa sebagian besar cerebral palsy dihasilkan dari perkembangan otak yang abnormal atau kerusakan otak pada saat melahirkan. Selain itu, kecelakaan, kekerasan, malpraktek, kelalaian, infeksi, dan cedera juga diketahui menjadi penyebab yang menyebabkan terjadinya cerebral palsy (https://www.cerebralpalsy.org/aboutcerebral-palsy/definition diakses pada Minggu, 26 Mei 2019).

Cerebral palsy bukanlah sebuah penyakit yang mengancam jiwa, melainkan sebuah kondisi, kecuali anak yang terlahir dengan kasus yang sangat parah. Dikarenakan cerebral palsy ini adalah sebuah kondisi, maka kerusakan yang terjadi pada otak tidak bisa disembuhkan atau dengan kata lain bersifat permanen, namun perawatan dan terapy dapat membantu mengatur dampaknya pada tubuh. Cerebral palsy ini juga bukanlah sesuatu yang menular, karena cerebral palsy terjadi disebabkan adanya kerusakan pada perkembangan otak. Sehingga, cerebral palsy ini bisa dikatakan sebagai kondisi yang kronis karena efeknya dalam jangka panjang atau seumur hidup.
Setiap kasus cerebral palsy yang terjadi pada setiap orang merupakan kasus yang unik. Seseorang mungkin mengalami kelumpuhan total dan membutuhkan perawatan yang teratur, namun kasus lain juga mungkin seseorang mengalami kelumpuhan parsial yang memiliki sedikit tremor dan membutuhkan sedikit bantuan. Masing-masing kasus unik tergantung dari tipe kerusakan dan waktu terjadinya kerusakan pada perkembangan

\section{Tipe Anak dengan Cerebral Palsy}

Cerebral palsy dapat dibagi ke dalam beberapa tipe motorik, sebagai berikut.

1. Spastik sebesar $80-90 \%$ merupakan bentuk paling umum. Otot terlihat kaku dan ketat. Muncul karena kerusakan korteks motorik (area motorik di otak).

2. Diskinesia sebesar $6 \%$ memiliki karakteristik gerakan involunteer seperti distonia, atetosis dan atau chorea. Muncul karena kerusakan area Ganglia Basalis di otak.

3. Ataxia sebesar 5\% memiliki karakteristik gerakan gemetar. Mempengaruhi keseimbangan dan kesadaran posisi dalam ruang. Muncul karena kerusakan pada area Cerebellum otak.

4. Tipe campuran. Sejumlah anak dengan cerebral palsy dapat memiliki dua tipe motorik yang berbeda, seperti spastik dan distonia.

Selanjutnya, cerebral palsy dapat mempengaruhi bagian tubuh yang berbeda misalnya.

a. Spastik Quadriplegia/ Bilateral yaitu mempengaruhi anggota gerak kedua lengan dan tungkai terpengaruh. Otot-otot batang tubuh, muka, mulut juga sering terpengaruhi.

b. Spastik Diplegia/ Bilateral yaitu mempengaruhi anggota gerak kedua tungkai terpengaruh, lengan juga mungkin terpengaruh, namun pada tingkat yang lebih rendah.

c. Spastik Hemiplegia/ Unilateral yaitu mempengaruhi anggota gerak salah satu sisi tubuh (satu lengan dan satu tangan). 


\begin{tabular}{|c|c|c|c|c|}
\hline $\begin{array}{c}\text { Focus: Jurnal } \\
\text { Pekerjaan Sosial }\end{array}$ & ISSN: $2620-3367$ & Vol. 2 No: 2 & Hal: $208-218$ & Desember 2019 \\
\hline
\end{tabular}

Selanjutnya, kemampuan motorik kasar pada anak dan remaja dengan kondisi cerebral palsy dapat dikategorikan menjadi lima tingkatan berbeda yang dikembangkan oleh CanChild di Kanada yaitu Sistem Klasifikasi Fungsional Motorik Kasar (GMFCS) pada gambar di bawah ini.

Gambar 1 Tingkatan Kemampuan Motorik Kasar Anak dengan Cerebral Palsy

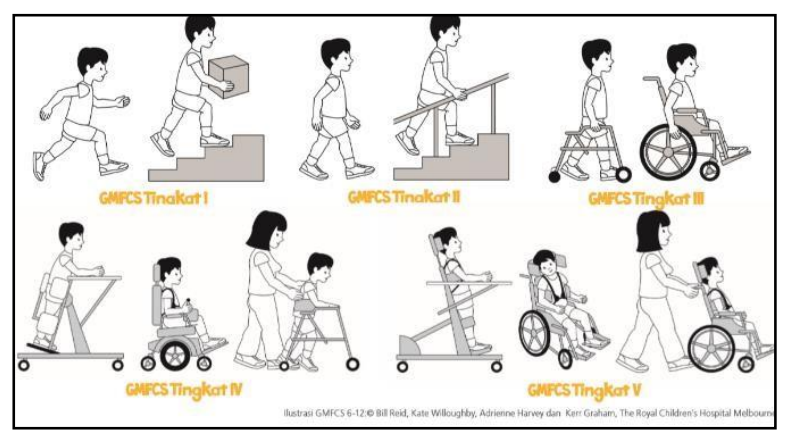

Selain itu, anak dengan kondisi cerebral palsy biasanya memiliki gangguan penyerta baik gangguan fisik maupun kognitif, menurut penelitian yang diterbitkan ke dalam sebuah poster dalam merayakan World Cerebral Palsy Day menyatakan bahwa terdapat 1 dari 3 anak tidak mampu berjalan, 1 dari 4 anak tidak dapat berbicara, 3 dari 4 anak mengalami nyeri, 1 dari 4 anak memiliki epilepsi, 1 dari 4 anak memiliki gangguan perilaku, 1 dari 2 anak memiliki gangguan intelektual, 1 dari 10 anak memiliki gangguan penglihatan yang berat, 1 dari 4 anak memiliki masalah mengontrol kandung kemih, 1 dari 5 anak memiliki gangguan tidur, dan 1 dari 5 anak memiliki masalah mengontrol air liur (https://www.cerebralpalsy.org, diakses pada 25 Mei 2019).

\section{Kebutuhan Orangtua Anak dengan Cerebral Palsy}

Keluarga merupakan institusi sosial pertama anak. Menurut Lestari (2012), keluarga dapat dibagi menjadi dua jenis yaitu keluarga inti (nuclear family) dan keluarga batih (extended family). Keluarga inti adalah keluarga yang di dalamnya hanya terdapat tiga posisi sosial, yaitu suami-ayah, istri-ibu, dan anak (Lee, 1982, dalam Lestari, 2012). Sedangkan keluarga batih adalah anggota keluarga besar, seperti kakek, nenek, paman, atau bibi (Inayah, 2011). Pada kenyataannya, anak dengan kondisi cerebral palsy bisa saja dirawat oleh orangtua (ayah dan ibu) dari keluarga inti, ataupun dari keluarga batih (extended family) yang sudah dianggap sebagai orangtua.
Peran orangtua sangat besar bagi tumbuh kembang anak. Bagi anak dengan cerebral palsy, orangtua berperan seperti manajer bagi kehidupan anak. Bagi orangtua yang memiliki anak dengan cerebral palsy, orangtua harus sangat beradaptasi terhadap berbagai perubahan yang terjadi, antara lain (Tim Dosen Fakultas Psikologi Unika Atma Jaya, 2018, hal. 35 36):

a. Identitas keluarga. Orangtua yang memiliki anak dengan cerebral palsy, tentu label yang diberikan oleh masyarakat bukanlah sebagai keluarga pada umumnya, namun keluarga akan memperoleh label "keluarga dengan anak dengan cerebral palsy". orangtua juga perlu bisa menerima anaknya dan berbagai kondisi yang ada.

b. Keuangan. Memiliki anak dengan cerebral palsy pastinya akan memerlukan biaya yang besar karena anak dengan cerebral palsy memerlukan berbagai kebutuhan dan penanganan lebih dari pada anak pada umunya, seperti biaya untuk terapi, guru pendamping, dan bahkan pengasuh khusus apabila orangtua bekerja. Sehingga orangtua perlu mempersiapkan anggaran yang besar untuk anaknya.

c. Aktivitas sosial dan rekreasi. Orangtua yang memiliki anak dengan cerebral palsy akan lebih memikirkan apabila ingin berkegiatan di tempat umum. Orangtua perlu memikirkan apakah tempat atau kegiatan tersebut merupakan tempat yang ramah bagi anaknya.

d. Berbagai keputusan penting. Orangtua juga perlu memikirkan terkait dengan pengambilan keputusan penting. seperti, bagi ibu bekerja yang memiliki anak dengan cerebral palsy harus mempertimbangkan apakah melanjutkan atau berhenti kerja dan fokus untuk mengasuh anaknya, apakah harus pindah ke tempat kerja yang lebih dekat dengan rumah sehingga lebih mudah mengontrol kondisi anak, dan lainnya.

e. Tahapan perkembangan. Terdapat masamasa dalam proses perkembangan anak yang membuat orangtua stres. Masa-masa itu adalah pada masa awal, orangtua harus menerima diagnosis yang diberikan akan kondisi anaknya. Kemudian, pada masa sekolah, orangtua harus mencari sekolah yang tepat bagi anak dan membantu anak agar dapat menyesuaikan diri di lingkungan luar. Pada masa remaja dan dewasa, orangtua harus menyiapkan anak agar siap dan melepaskannya ke dunia dewasa yang sesungguhnya menuntut kemandirian anak. 


\begin{tabular}{|c|c|c|c|c|}
\hline $\begin{array}{c}\text { Focus: Jurnal } \\
\text { Pekerjaan Sosial }\end{array}$ & ISSN: $2620-3367$ & Vol. 2 No: 2 & Hal: $208-218$ & Desember 2019 \\
\hline
\end{tabular}

Orangtua perlu menyiapkan berbagai strategi khusus dan tepat pada masa-masa tersebut.

Dengan banyaknya kebutuhan dan tuntutan, serta berbagai dinamika yang terjadi pada orangtua yang memiliki anak dengan cerebral palsy, orangtua menjadi rentan terkena stres. Stressor merupakan sumber penyebab stres. Stressor yang dirasakan orangtua dapat dikategorikan menjadi beberapa jenis (Rice, 1992) yaitu.

1. Stressor individu adalah sumber stres yang berasal dari dalam diri seseorang. Orangtua yang memiliki anak dengan cerebral palsy harus bisa menerima kondisi anaknya dan beradaptasi dengan kondisi yang ada. Hal tersebut pada umumnya menyebabkan stres pada orangtua.

2. Stressor interpersonal adalah sumber stres yang berhubungan dengan pada saat proses berinteraksi dengan orang lain. Orangtua yang memiliki anak dengan cerebral palsy juga harus memberikan informasi terkait dengan kondisi anaknya kepada orang lain, seperti keluarga, teman, dan orang di sekitarnya. Orangtua perlu terbuka atas kondisi anaknya, karena penerimaan orang lain, baik itu keluarga maupun masyarakat, sangat diperlukan agar orangtua mendapatkan support yang dibutuhkan (Tim Dosen Fakultas Psikologi Unika Atma Jaya, 2018, hal. 39).

3. Stressor lingkungan fisik adalah sumber stres yang berasal dari lingkungan fisik di sekitar individu. Orangtua yang memiliki anak dengan cerebral palsy perlu memikirkan bagaimana lingkungan fisik yang berada di sekitar, khususnya lingkungan fisik di mana anaknya berada.

4. Stressor sosial adalah sumber stres yang berasal dari kehidupan sosial seseorang. Masyarakat terkadang masih memberikan label atau stigma-stigma yang kurang supportif bagi orangtua yang memiliki anak dengan cerebral palsy, stigma-stigma tersebut akan menimbulkan perilaku-perilaku yang berbeda pula dari masyarakat terhadap orangtua yang memiliki anak dengan cerebral palsy.

5. Stressor organisasi adalah sumber stres yang dapat terjadi pada seting tertentu, misalnya di dalam sebuah pekerjaan dan budaya organisasi yang tidak baik. Orangtua yang memiliki anak dengan cerebral palsy perlu memikirkan mengenai pekerjaannya, dan lainnya.
Orangtua yang memiliki anak dengan cerebral palsy memiliki kebutuhan khusus dari pada orangtua yang memiliki anak pada umumnya. Menurut penelitian yang dilakukan oleh Lestari,dkk (2018) mengungkapkan terdapat kebutuhan yang diperlukan baik bagi ibu dan ayah yang memiliki anak disabilitas. Pada ibu jika diurutkan dari tertinggi ke terendah adalah kebutuhan informasi dan dukungan profesional $71,0 \%$, pelayanan komunitas 64,5\%, menjelaskan kepada orang lain $38,7 \%$, kebutuhan finansial 22,6\%, perawatan anak $16,1 \%$, dan dukungan keluarga/sosial $12,9 \%$. Kebutuhan ayah dari tertinggi ke terendah yaitu kebutuhan informasi $71,0 \%$, pelayanan komunitas $64,5 \%$, dukungan profesional $61,0 \%$, menjelaskan kepada orang lain $45,2 \%$, kebutuhan finansial $29,0 \%$, perawatan

anak 22,6\%, dan dukungan keluarga/sosial 19,4\%. Dari perbandingan kebutuhan ayah dan ibu, keduanya memiliki kebutuhan tertinggi yaitu akan kebutuhan untuk mengakses informasi terkait dengan anaknya dan dunia disabilitas.

Dari penjelasan di atas, orangtua yang memiliki anak dengan cerebral palsy memiliki kebutuhan akan informasi dan dukungan profesional, kebutuhan untuk menerima kondisi yang ada, kebutuhan untuk beradaptasi dengan kondisi yang baru, kebutuhan menjelaskan kepada orang lain, kebutuhan finansial, kebutuhan akan perawatan anak, dan dukungan sosial

\section{Peran Support Group bagi Orangtua Anak dengan Cerebral Palsy}

Dalam menangani hal terkait dengan orangtua yang memiliki anak dengan kondisi cerebral palsy, pekerja sosial memiliki peranan penting. Menurut Skidmore dan Thackeray (1988, dalam Wibhawa, Raharjo, \& Santoso, 2010) pekerjaan sosial merupakan suatu bidang keahlian yang memiliki kewenangan untuk melaksanakan berbagai upaya guna meningkatkan kemampuan orang dalam melaksanakan fungsi-fungsi sosialnya melalui proses interaksi; agar orang dapat menyesuaikan diri dengan kondisi kehidupannya secara memuaskan. Pekerjaan sosial mengintervensi ketika seseorang berinteraksi dengan lingkungannya. Prinsip-prinsip hak asasi manusia dan keadilan sosial merupakan hal yang fundamental bagi pekerjaan sosial. Di dalam pekerjaan sosial memiliki beberapa level intervensi yaitu level mikro, mezzo, dan makro. Di dalam praktik pekerjaan sosial level mikro, terdapat intervensi pekerjaan sosial dengan kelompok (Groupwork). 


\begin{tabular}{|c|c|c|c|c|}
\hline $\begin{array}{c}\text { Focus: Jurnal } \\
\text { Pekerjaan Sosial }\end{array}$ & ISSN: $2620-3367$ & Vol. 2 No: 2 & Hal: $208-218$ & Desember 2019 \\
\hline
\end{tabular}

Skidmore, Thackeray, dan Farley (1994, dalam Adi, 2013) menyatakan groupwork adalah

"a method of working with people in groups (two or more people) for the enhancement of social functioning and for achienvement of socially desirable goals. Group work is based on knowledge of people's need for each other and their interdependence. Groupwork is a method of reducing or eliminating road-blocks to social interraction and for accomplishing socially desirable purposes."

Intervensi pekerjaan sosial dengan kelompok atau social groupwork ini dapat memberikan solusi atas permasalahan di atas yang mana orangtua yang memiliki anak dengan cerebral palsy memerlukan sistem pendukung (support system) sehingga orangtua memperoleh dukungan sosial yang dibutuhkan dan dapat menjalankan peran dan fungsinya dengan optimal. Solusi yang bisa ditawarkan oleh pekerja sosial adalah dengan membuat support group bagi para orangtua yang memiliki anak dengan cerebral palsy.

Pada dasarnya, support group ini masih masuk ke dalam intervensi kelompok untuk penyembuhan atau group therapy intervention. Terdapat beberapa asumsi universal terkait dengan group therapy intervention (Ezhumalai, Muralidhar, Dhanasekarapandian, \& Nikketha, 2018) yaitu.

a. Pengalaman kelompok bersifat universal.

b. Kelompok terapi digunakan untuk melakukan perubahan pada perilaku dan kebiasaan.

c. Kelompok dapat memberikan perubahan yang lebih bersifat permanen.

d. Kelompok berperan sebagai instrumen untuk menolong sesama.

e. Melalui kelompok, anggota di dalamnya dapat tumbuh dan berkembang bersama.

f. Lebih mudah melakukan perubahan dengan media kelompok dari pada secara individual.

Selanjutnya, dijelaskan mengenai fungsi dari kelompok terapi yaitu corrective, developmental, educative, preventive, recreational, dan therapeutic. Kelompok terapi ini cocok untuk orang-orang yang memiliki gangguan stres pascatraumatis (Shelby,1994), gangguan kecemasan, gangguan penyimpangan oposisional, gangguan depresif, gangguan disruptif, gangguan perilaku, dan gangguan perkembangan tertentu (Gupta,
Hariton, dan Kernberg, 1996, dalam Geldard \& Geldard, 2013).

Support group merupakan kelompok yang terdiri dari beberapa orang yang memiliki permasalahan yang sama, mereka saling berdiskusi mengenai masalahnya dan memberikan dukungan kepada masing-masing anggota kelompok. Tujuan utama dari kelompok ini adalah memberikan suatu dukungan, namun juga tidak dipungkiri bahwa kelompok ini juga dapat menghasilkan perubahan pada aspek emosional, kognitif, dan perilaku para anggota di dalamnya.

Cara kerja support group ini dengan sistem mutual aid. Lebih lanjut dijelaskan oleh Shulman (2010) dalam McDermott (tahun?). Pada bab yang membahas tentang Working with therapeutic groups dijelaskan 10 cara kerja kelompok sebagai sistem mutual aid, yaitu.

1. Sharing thoughts, feelings, ideas.

2. Establishing dialogue and a dialectical process.

3. Entering taboo areas regarding topics are often not able to be talked about elsewhere.

4. Recognising that members are 'all-in-sameboat' and derving comfort from this.

5. Developing a universal perspective, shared by group members.

6. Offering mutual support where possible.

7. Making mutual demand when the need arises.

8. Providing space in the group for individual problem solving.

9. Providing space in the group for rehearsal, that is, trying out solutions before applying them in 'real life'.

10. Becoming more resilient by recognizing the 'strengths-in-numbers' which group participation represents.

Menurut Hutchinson (2008, dalam Rahmania, Nurwati, \& Taftazani, 2016).

It should also be noted that parent's lives are influenced by the trajectories of their children's lives. For example, parents may need to alter their work trajectories to respond to the needs of a terminally illchild. Or parents may forgo early retirement to assist their young adult children with education expenses. Parents may be negatively affected by stressful situations that their children face.

Dari pendapat Hutchinson, dapat ditarik makna bahwa orangtua yang memiliki anak dengan 
kondisi sakit atau berbeda, dan dalam konteks ini adalah orangtua yang memiliki anak dengan cerebral palsy, kondisi anaknya akan mempengaruhi kondisi orangtua dan bisa menyebabkan stres. Kondisi tersebut juga akan mempengaruhi tingkat kesejahteraan orangtua yang pada akhirnya juga mempengaruhi kesejahteraan anak.

Secara umum, Geldard dan Geldard (2013) memberikan intervensi dengan menggunakan memiliki beberapa manfaat yaitu.

a. Kelompok bisa meningkatkan perubahan.

b. Kelompok bisa disejajarkan dengan lingkungan sosial yang lebih luas.

c. Kelompok menumbuhkan rasa memiliki.

d. Kebutuhan-kebutuhan yang bersifat umum dapat terpenuhi melalui kelompok.

e. Kelompok lebih efektif, terutama dari segi biaya.

Banyak peranan yang dapat dilakukan oleh pekerja sosial terkait dengan anak dengan cerebral palsy dan keluarganya, baik dalam pemberian pelayanan individu dan kelompok. Pelayanan yang diberikan bisa dilakukan secara individual yaitu berupa konseling dan pekerja sosial juga dapat memberikan pelayanan secara kelompok yaitu dengan support group.

Support group dapat menyediakan sebuah tempat yang aman dari stigma-stigma lingkungan sosial bagi para anggotanya dalam menyalurkan perasaan-perasaannya, memberikan para anggotanya dalam membuat perspektif baru terkait dengan kondisi yang dihadapi. Di dalam sebuah kondisi yang sangat kondusif, para partisipan atau anggota kelompok dapat secara terbuka membicarakan permasalahannya dan melepaskan bebannya, serta dapat secara perlahan menghapus kepercayaan atau pandangan buruk dari diri sendiri atau self-destructive beliefs (Corey \& Corey, 2006). Para partisipan juga akan mulai memaafkan diri mereka sendiri dan membuat keputusan terkait dengan apa yang bisa mereka lakukan pada waktu yang ada (Corey \& Corey, 2006). Tujuan dari kelompok ini adalah memberikan dukungan, namun melalui kelompok ini juga dapat menghasilkan perubahan pada aspek emosional, kognitif, dan perilaku individu yang ada di dalamnya (Geldard \& Geldard, 2013). Kelompok pada dasarnya memberikan beberapa manfaat kepada para individu di dalamnya antara lain terpenuhinya (a) kebutuhan untuk mencintai dan dicintai, (b) kebutuhan akan penerimaan, (c) kebutuhan kasih sayang, (d) kebutuhan untuk merasa berharga, dan (e) kebutuhan akan pengalaman baru (Geldard \& Geldard, 2013).

Support group memiliki kekuatan penyembuhan dan memberikan efek therapeutic karena seseorang mendapatkan dukungan yang sifatnya timbal balik, sehingga memunculkan rasa kebersamaan, pemahaman diri, dan harapan baru (Tirzi, Pane, Taufik, \& Nuryanti, 2016). Support group therapy adalah suatu proses terapi pada suatu kelompok yang memiliki permasalahan yang sama untuk mengkondisikan dan memberi penguatan pada kelompok maupun perorangan dalam kelompok sesuai dengan permasalahannya (Seligman \& Marhsak, 1990). Support group therapy ini merupakan cara pemberian terapi atau intervensi yang mana di dalamnya terdapat individu-individu yang relatif memiliki permasalahan yang sama. Mereka saling bercerita dan berdiskusi tentang masalahnya dan solusi dari permasalahan yang dialami. Di dalam kelompok dukungan tersebut juga terjadi proses saling belajar dan menguatkan, dengan tujuan utama tercapainya kemampuan untuk mengnangani masalah (coping) yang efektif terhadap masalah ataupun trauma yang dialami (Yuniardi, 2011). Dalam prakteknya, pekerja sosial dapat memiliki banyak peran antara lain sebagai fasilitator, penyintensis, pendukung, dan pembuat norma (Damanik \& Pattiasina, 2009).

Di dalam kelompok ini, orangtua yang memiliki anak dengan cerebral palsy dapat memperoleh dukungan dan terpenuhi kebutuhannya, yakni kebutuhan untuk mencintai dan dicintai, kebutuhan akan penerimaan, kebutuhan kasih sayang, kebutuhan untuk merasa berharga, dan kebutuhan akan pengalaman baru. Apabila orangtua mendapatkan dukungan dan kebutuhan yang dibutuhkan, maka orangtua dapat menjalankan perannya sebagai orangtua terhadap anaknya yang memiliki kondisi cerebral palsy. Dengan demikian pula, apabila orangtua dapat menjalankan perannya dengan baik dan terpenuhi kebutuhannya, maka akan berdampak baik terhadap perkembangan anaknya.

Apabila dikaitkan dengan sistem dasar pekerjaan sosial, orangtua anak dengan cerebral palsy adalah sebagai sistem sasaran. Di dalam pekerjaan sosial, terdapat empat sistem dasar dalam praktek pekerjaan sosial. Kemampuan ini menunjukkan kemampuan Pekerja Sosial dalam mengajak klien maupun orang-orang atau sistem sosial yang terkait dengan pemecahan sosial. Adapun sistem dasar tersebut yaitu. 


\begin{tabular}{|c|c|c|c|c|}
\hline $\begin{array}{c}\text { Focus: Jurnal } \\
\text { Pekerjaan Sosial }\end{array}$ & ISSN: $2620-3367$ & Vol. 2 No: 2 & Hal: $208-218$ & Desember 2019 \\
\hline
\end{tabular}

1. Sistem klien. Di dalam sistem klien ini adalah orang-orang yang bermasalah dan membutuhkan bantuan.

2. Sistem sasaran adalah yaitu orang-orang yang harus diubah terlebih dahulu diubah agar tujuan pemberian bantuan kepada sistem klien dapat tercapai.

3. Sistem kegiatan adalah orang atau lembaga yang karena kewenangannya atau kompensasinya diajak bersama oleh pelaksana perubahan.

4. Sistem pelaksana perubahan adalah orangorang yang ada di lembaga yang melaksanakan kegiatan pertolongan. (Wibhawa, Raharjo, \& Santoso, 2010).

Orangtua dengan cerebral palsy merupakan orang-orang yang perlu diubah terlebih dahulu agar tujuan pemberian bantuan terhadap klien, yaitu anak dengan cerebral palsy, dapat tercapai. Dengan adanya, support group bagi orangtua anak dengan cerebral palsy, diharapkan orangtua dapat memperoleh dukungan dan bantuan yang dibutuhkan. Dengan demikian, orangtua dapat menjalankan perannya sebagai orangtua dengan optimal, sehingga anak dengan cerebral palsy akan mengalami perkembangan yang progresif. Hal ini dapat terjadi karena anak yang waktu sehari-harinya banyak dihabiskan di rumah bersama orangtua akan mendapatkan pelayanan juga dari orangtua, bukan hanya dari terapis dan sekolah.

\section{Kesimpulan}

Cerebral palsy merupakan salah satu jenis disabilitas fisik. Cerebral palsy ini bukan sebuah penyakit, melainkan sebuah kondisi. Sehingga, kondisi ini bersifat tidak bisa disembuhkan atau menetap. Maka, orangtua yang memiliki anak dengan kondisi cerebral palsy harus menghadapi anaknya dengan kondisi tersebut dalam jangka waktu panjang, bahkan seumur hidup. Sehingga, keluarga, khususnya orangtua di sekitar anak dengan cerebral palsy, perlu memahami informasi terkait dengan cerebral palsy dan kondisi anaknya, serta bagaimana penanganan yang tepat untuk anak dengan cerebral palsy.

\section{Daftar Pustaka}

Corey, M. S., \& Corey, G. (2006). Groups : Process and Practice Sevent Edition. Fullerton: Thomson Brooks/Cole.
Orangtua yang memiliki anak dengan cerebral palsy berpeluang lebih besar untuk menghadapi kondisi yang menyebabkan stres. Stres dapat bersumber dari internal dan eksternal diri orangtua. Dengan demikian, orangtua yang memiliki anak dengan cerebral palsy memerlukan dukungan sosial. Dukungan sosial merupakan bantuan dari keluarga, teman, dan orangorang sekitar, bahkan dari orang yang mengalami permasalahan yang sama. Dukungan sosial dapat berupa bantuan instrumental, informasi, dukungan emosional, dan penghargaan.

Pekerja sosial dapat berperan dalam menangani hal ini. Pekerja sosial dapat memberikan pelayanan secara individual maupun kelompok kepada keluarga, khususnya orangtua agar mereka dapat memperoleh dukungan sosial yang dibutuhkan. Pelayanan kelompok yang dapat diberikan adalah melalui support group. Support group adalah kelompok yang terdiri dari beberapa individu yang memiliki permasalahan yang relatif sama. Di dalam kelompok tersebut, masingmasing saling bercerita mengenai permasalahannya dan saling memberikan solusi atas masalahnya tersebut. Di dalam kelompok tersebut juga akan terjadi proses pemberian dukungan sosial, baik secara emosional, informasi, intrumental, atau pun penghargaan.

Apabila orangtua mendapatkan dukungan sosial yang dibutuhkan, maka orangtua dapat menjalankan perannya sebagai orangtua terhadap anaknya yang memiliki kondisi cerebral palsy. Dengan demikian pula, apabila orangtua dapat menjalankan perannya dengan baik dan terpenuhi kebutuhannya, maka akan berdampak baik terhadap perkembangan anaknya yang memiliki kondisi cerebral palsy.

Support group merupakan wadah bagi orangtua dalam mendapatkan dukungan sosial dan juga sebagai sarana dalam memproses apa yang terjadi. Di dalam support group ini menggunakan kekuatan yang ada di kelompok untuk mengintervensi individu di dalamnya. Dengan demikian, support group dapat mengembalikan keberfungsian sosial para individu di dalamnya.

Creswell, J. W. (2010). Research Design. Pendekatan Kualitatif, Kuantitatif dan Mixed. Edisi Ketiga (Terjemahan). Yogyakarta: Pustaka Pelajar. 
Focus: Jurnal

Pekerjaan Sosial
Damanik, J., \& Pattiasina, C. (2009). Buku Pintar Pekerjaan Sosial - Jilid 2. Jakarta: Gunung Mulia.

Delphie, B. (2006). Pembelajaran Anak Berkebutuhan Khusus dalam Setting Pendidikan Inklusi. Bandung: Refika Aditama.

Eliyanto, H., \& Hendriani, W. (2013). Hubungan Kecerdasan Emosi dengan Penerimaan Ibu Terhadap Anak Kandung yang Mengalami Cerebral Palsy. Jurnal Psikologi dan Perkembangan Vol.2 No. 2, 124-130.

Ezhumalai, S., Muralidhar, D., Dhanasekarapandian, R., \& Nikketha, B. S. (2018). Group Interventions. Indian Journal of Psychiatry, 514-521.

Fauzan, H., Amin , M., Gustiawan, \& Patimasang, S. (2018). Peranan Komunikasi Orangtua Dalam Pembentukan Kepribadian Anak. ResearchGate, 1-9.

Geldard, K., \& Geldard, D. (2013). Menangani Anak dalam Kelompok : Panduan untuk Konselor, Guru, dan Pekerja Sosial. Yogyakarta: Pustaka Pelajar.

Handojo, Y. (2003). Autisma : Petunjuk Praktis dan Pedoman Materi Untuk Mengajar Anak Normal, Autis, dan Perilaku Lain. Jakarta: PT. Bhuana Ilmu Populer.

Hidayati, N. (2011). Dukungan Sosial bagi Keluarga Anak Berkebutuhan Khusus. INSAN Vol. 13 No. 01, 15-20.

Inayah, N. (2011). Model Pola Asuh Ayah Dalam Keluarga Migran Di Kabupaten Banyuwangi. Annual International Conference on Islamic Studies (AICIS XII), (hal. 2553-2567).

Kementerian Kesehatan Republik Indonesia. (2014). Buletin Jendela Data dan Informasi Kesehatan : Situasi Penyandang Disabilitas. Jakarta: Kementerian Kesehatan RI.

Kementerian Pemberdayaan Perempuan dan Perlindungan Anak Republik Indonesia. (2013). Panduan Penanganan Anak Berkebutuhan Khusus Bagi Pendamping (Orangtua, Keluarga, dan Masyarakat). Jakarta: Kementerian Pemberdayaan Perempuan dan Perlindungan Anak Republik Indonesia.
Lestari, S. (2012). Psikologi Keluarga: Penanaman Nilai dan Penanganan Konflik dalam Keluarga. Jakarta: Prenada Media Group.

Lestari, S., Yani, D. I., \& Nurhidayah, I. (2018). Kebutuhan Orangtua Dengan Anak Disabilitas. JNC Volume 1 Nomor 1, 50-59.

Listiani, F., \& Savira, S. I. (2015). Penerimaan Diri Remaja Cerebral Palsy. Character Volume 3 Nomor 2, 1-6.

Maimunah, S. (2013). Studi Eksploratif Perilaku Koping Pada Individu Dengan Cerebral Palsy. Jurnal Imliah Psikologi Terapan Vol. 1 No. 1, 156-171.

Our Community Pty Ltd . (2015). Working with Therapeutic Groups. Dalam F. McDermott, Doing it Together. A Collection of Approaches, Experiences and Purposes of an in Groups, Committees, Organisations, Networks and Movements (hal. 112-122). Melbourne: Our Community Pty Ltd .

Setiawan, A., Suryaningsih, \& Solina, E. (t.thn.). Peran Orangtua Terhadap Anak Berkebutuhan Khusus Di SLBN Bintan. 1-12.

Sriwidodo. (1985). Cermin Dunia Kedokteran. Jakarta: Penerbit Pusat Penelitian dan Pengembangan PT. Kalbe Farma.

Supriyanto, A. (2012). Peran Pengasuhan Orangtua Anak Berkebutuhan Khusus Dalam Aktivitas Olahraga. Proceeding Seminar Nasional, (hal. 1-11). Surakarta.

Susilowati, A. T. (2007). Hubungan Dukungan Sosial Dan Tingkat Stress Orangtua Dari Anak Autis.

Tim Dosen Fakultas Psikologi Unika Atma Jaya. (2018). Mempersiapkan Generasi Milenial Ala Psikolog. Jakarta: Buku Kompas.

Tirzi, R. P., Pane, R. I., Taufik, N., \& Nuryanti, T. (2016). Pengembangan Support Group Untuk Remaja Korban Kekerasan Seksual. Researchgate, 1-11.

Undang-Undang Nomor 8 Tahun 2016 Tentang Penyandang Disabilitas. (2016).

Vani, C. G., Raharjo, S. T., Hidayat, E. N., \& Humaedi, S. (2016). Pengasuhan (Good Parenting) Bagi Anak Dengan Disabilitas. 122-128. 


\begin{tabular}{|c|c|c|c|c|}
\hline $\begin{array}{c}\text { Focus: Jurnal } \\
\text { Pekerjaan Sosial }\end{array}$ & ISSN: 2620-3367 & Vol. 2 No: 2 & Hal: $208-218$ & Desember 2019 \\
\hline
\end{tabular}

Wibhawa, B., Raharjo, S. T., \& Santoso, M. B. (2010). Dasar-Dasar Pekerjaan Sosial : Pengantar Profesi Pekerjaan Sosial. Bandung: Widya Padjadjaran.

Yuniardi, M. (2011). Support Group Therapy Untuk Mengembangkan Potensi Resiliensi Remaja Dari Keluarga Single Parent Di Kota Malang. Psikobuana Vol. 3 No. 2, 135-140.

\section{Sumber Lainnya :}

https://www.cerebralpalsy.org/about-cerebral-

palsy/definition diakses pada Minggu, 26 Mei 2019

pukul 20.34 WIB.

https://worldcpday.org/wp-

content/.../WCPD_What_is_CP_Poster_Indonesia.pdf diakses pada Minggu 26 Mei 2019 Pukul 21.14 WIB.

https://www.nejm.org/doi/pdf/10.1056/nejmra055549

diakses pada Rabu, 13 Juni 2019 pukul 13.20 WIB.

https://www.msdmanuals.com/home/brain,-spinal-

cord,-and-nerve-disorders/movement-

disorders/chorea,-athetosis,-and-hemiballismus diakses pada Rabu, 13 Juni 2019 pukul 13.27 WIB.

https://www.honestdocs.id/chorea diakses pada Rabu, 13 Juni 2019 pukul 13.31 WIB. 